Article

\title{
An Approach to Evaluating Light Pollution in Residential Zones: A Case Study of Beijing
}

\author{
Xueting Jin ${ }^{1,2,3}$, Yu Li ${ }^{1,2}$, Jinzhou Zhang ${ }^{3,4}$, Ji Zheng ${ }^{1}$ and Huiping Liu ${ }^{3, *}$ \\ 1 Institute of Geographic Sciences and Natural Resources Research, Chinese Academy of Science, \\ Beijing 100101, China; xtingjin@163.com (X.J.); liy@igsnrr.ac.cn (Y.L.); zhengj.13s@igsnrr.ac.cn (J.Z.) \\ 2 College of Resource and Environment, University of Chinese Academy of Sciences, Beijing 100049, China \\ 3 School of Geography, Beijing Normal University, Beijing 100875, China; jinzhouzgis@gmail.com \\ 4 School of Geographic Sciences and Urban Planning, Arizona State University, Tempe, AZ 85287, USA \\ * Correspondence: hpliu@bnu.edu.cn; Tel.: +86-10-5880-7455
}

Academic Editor: Marc A. Rosen

Received: 14 March 2017; Accepted: 14 April 2017; Published: 19 April 2017

\begin{abstract}
Outdoor lighting is becoming increasingly widespread, and residents are suffering from serious light pollution as a result. Residents' awareness of their rights to protection has gradually increased. However, due to the sometimes-inaccessible nature of residential vertical light incidence intensity data and the high cost of obtaining specific measurements, there is no appropriate hierarchic compensation for residents suffering from different degrees of light pollution. It is therefore important to measure light pollution levels and their damage at the neighborhood scale to provide residents with basic materials for proper protection and to create more politically-suitable solutions. This article presents a light pollution assessment method that is easy to perform, is low-cost and has a short data-processing cycle. This method can be used to monitor residential zone light pollution in other cities. We chose three open areas to test the spatial variation pattern of light intensity. The results are in accordance with spatial interpolation patterns and can be fit, with high precision, using the inverse distance weighted interpolation (IDW) method. This approach can also be used in three dimensions to quantitatively evaluate the distribution of light intensity. We use a mixed-use zone in Beijing known as The Place as our case study area. The vertical illumination at the windows of residential buildings ranges from 2 lux to 23 lux; the illumination in some areas is far higher than the value recommended by CIE. Such severe light pollution can seriously interfere with people's daily lives and has a serious influence on their rest and health. The results of this survey will serve as an important database to assess whether the planning of night-time lighting is scientific, and it will help protect the rights of residents and establish distinguished compensation mechanisms for light pollution.
\end{abstract}

Keywords: light pollution; monitoring approach; spatial distribution; residential zone; Beijing

\section{Introduction}

Outdoor lighting is an indispensable element of modern civilized societies, and the expanding use of light at night is due to the fact that humans are trying to extend the duration of their daily activities. However, lacking a unified standard for urban nightscape lighting, night-time lighting is generally disordered, and it has become common practice to compare brightness not only among cities, but also within different parts of the same city. Light pollution has become one of the main elements of environmental pollution [1] and is described as "One of the most rapidly increasing alterations to the natural environment" [2]. The annual increase in the brightness of the night sky will not fall below $3 \%$, and at this rate, it will double within 23 years [3]. Since 1973, Kurt has defined light pollution as unwanted sky light produced by man as a result of population growth and increased outdoor 
illumination per capita [4], which contains several aspects: the intensity, spectra, duration and timing of light $[5,6]$.

Excessive and misdirected light exhibits many of the characteristics of a negative externality. The influence of light pollution was first discovered by the atmospheric sciences. Light pollution reduces the visibility of galaxies, nebulae and other celestial objects, forcing astronomical observatories to find new locations [4,7,8]; it also causes enormous aesthetic damage [9]. Light pollution increases both energy use and carbon dioxide emissions. In the United States, approximately $6 \%$ of the electricity produced is used for outdoor lighting, and an estimated 30\% of this is wasted as light pollution [10]. Light pollution also causes damage to wildlife: it disrupts the migration patterns of nocturnal birds and is a lethal cause of mosquitos [8,11,12]. In the worst-case scenario, light pollution may even affect the entire ecological balance of the local environment [13]. Furthermore, human physiology is not immune to the problem of excessive and poorly-directed light. Excessive illumination near people's living environments may influence their health [14,15], and even lighting as low as 1.5 lux can affect human circadian rhythms [16]. Light pollution can decrease the production of melatonin [7], leading to insomnia and even cancer $[13,16,17]$. Metropolitan areas, with their larger proportions of urbanized land, centralized populations and intensive socioeconomic activities, are becoming major sources of artificial lighting, which will adversely affect their citizens [18]. This compelling evidence of the adverse effects of night-time artificial light should be balanced against lighting's supposed positive effects on safety and security, although current studies have not proven that light levels have any effect on crime rates [19].

Before efficient mitigation policies can be developed, it is essential to analyze the spatial distribution of light pollution and to quantify its damages [20]. Current research about light pollution mainly focuses on two aspects, the intensity and spectra [6], and the result shows that the spectra may have greater influence on residents [21]. However, with the prevalent use of electronic screens, scrolling and showing videos and advertisements in metropolises like Beijing, it is hard to quantify the wavelength and its effect in a real city even at a street scale. Therefore, the conception defined by Cinzano et al. is used here, describing light pollution as the alteration of ambient light levels in the night environment produced by man-made light [2], and we will focus on the light intensity and its influence. Studies have analyzed the light pollution situations of many countries and metropolitan areas around the world, including Finland [22], Los Angeles [4], Athens [23] and Hong Kong [18]. Current studies usually use remote sensing data at the spatial level of the city or above. These studies have provided strong support for limiting light pollution. China has many different regions, each with its own socioeconomic and environmental characteristics [24], and even in the same city, different zones have different light levels and lighting criteria due to their different land use functions $[25,26]$. Therefore, light pollution trends can change drastically across different spatial scales [27]. However, in comparison to the ever-increasing amount of night-time lighting in China, the specific and land use-oriented assessment and management of light pollution and associated planning are still underdeveloped [28].

The most difficult areas in which to balance light intensity are mixed-use zones, especially where residential zones are in close proximity to commercial zones. IDA (International Dark-Sky Association) has suggested that zones with high levels of light should yield to zones with low levels of light [26]. The citizens of China's metropolises continue to suffer from severe light pollution, which demands prompt solutions [27]. For example, more than half of the citizens of Guangzhou have reported feeling uncomfortable due to light pollution [29]; and LED (Light Emitting Diode) screen had influenced the daily life of the residents in Shenzhen [30]. Thus, it is important to measure levels of light pollution and the damage that such pollution causes to neighborhoods to provide residents with the basic materials for proper protection and to create more politically-suitable solutions. However, for a variety of reasons, including privacy and cost, we cannot monitor the light intensity at every residential window, and thus, we cannot evaluate the light contamination situation in every home. GIS technology has proven extremely useful for spatial analysis [23,31], and we use ArcGIS 10.1 to build a model to analyze the light pollution situations of residential zones. 
In 1997, Beijing launched a large-scale urban nightscape lighting initiative, and it has since created an urban nightscape lighting system centered on Tiananmen Square, with an emphasis on Chang An Avenue and the north-south axis. Compared with developed countries, China has fewer studies and laws related to light pollution [32], and the country's light pollution problems have only gradually emerged. Here, we use Beijing as an example, as the city has been designated a seriously light-polluted area by Science Advance [33]. Using GIS spatial analysis technology, this study presents a light pollution assessment method of residential zones that can sometimes be inaccessible that is easy to perform, is low-cost, and has short data-processing cycle and some advice are put forward. We hope this can provide a reference for residents wanting to avoid light pollution, for relevant departments wanting to formulate management measures and for metropolises wanting to reduce their light pollution.

\section{Method, Observation and Source of Data}

\subsection{Outline of the Survey}

Due to the inaccessibility of residential vertical incidence intensity data, we chose three open areas to test the spatial variation patterns of light intensity. Then, we evaluated the accuracy of the approach that we had chosen to monitor the distribution of light intensity, and the pattern was used to analyze the light-contamination situation of residents. Xidan, Wangfujing and Zhongguancun were used as open zones to test spatial variation patterns of light intensity. These zones are all typical flourishing commercial zones. For example, the Xicheng district government has chosen a development approach focused on the prosperity of Xidan and on driving regional economic development. Thus, in recent years, the Xicheng district government has reconstructed and renovated Xidan's external environment; it has used decorated, illuminated advertisements and other amenities to enhance the effects of night-time lighting. This creates complicated point, line and area light sources in these zones, which can reflect if the distribution pattern has high adaption. The residential area where we have chosen to study light pollution is the Dongdaqiao community. This is a mixed-use zone containing a flourishing commercial zone and a quiet residential zone where the majority of the damage and complaints are due to light pollution. The commercial zone is known as The Place, the flagship commercial area of the central business district located in Beijing's Chaoyang district. The Place is quite famous for its electronic screen that is $250 \mathrm{~m}$ in length and $30 \mathrm{~m}$ in width, which has brought fantastical acousto-optic combinations to the entire street and has become a world-class spectacle that attracts large crowds of people. However, just across the road, approximately 60 meters away, there is a residential zone where we will quantify the level of light pollution.

To build a model of the spatial distribution of light intensity at the street scale, it is essential to measure the characteristics and dimensions of buildings, as well as light sources and their intensities. We use high-resolution remote sensing images from Google Earth to acquire the location of each building, and we use the relative location to acquire the location of each light source. We also estimated the length of the line light source, the length and width of the area light sources, light color and other properties; building height is measured with a laser rangefinder. The layout of the sampling site generally follows a uniform distribution, and the density of sample points is increased in the area of complex light sources and rapidly changing light intensities. The measurement interval of the commercial zone is $20 \mathrm{~m}$ (Figure 1), and it is $10 \mathrm{~m}$ in the mixed-use zone (Figure 2). At every sample point of the commercial and residential zones, we measure light intensity at $1.5 \mathrm{~m}$ above ground (the average person's height) from four orientations (east, south, west, north), and the average of the four values is considered the light intensity of this sample point (Table 1). In the mixed-use area, we add two sample point layers, at heights of $0 \mathrm{~m}$ and $3 \mathrm{~m}$. These research data were collected with the lux meter (model: HT-8318; resolution: 0.1 lux; range: 0 400 Klux) and the range finder (models: PD42; resolution: $0.001 \mathrm{~m}$; range: $0 \sim 200 \mathrm{~m}$ ). 


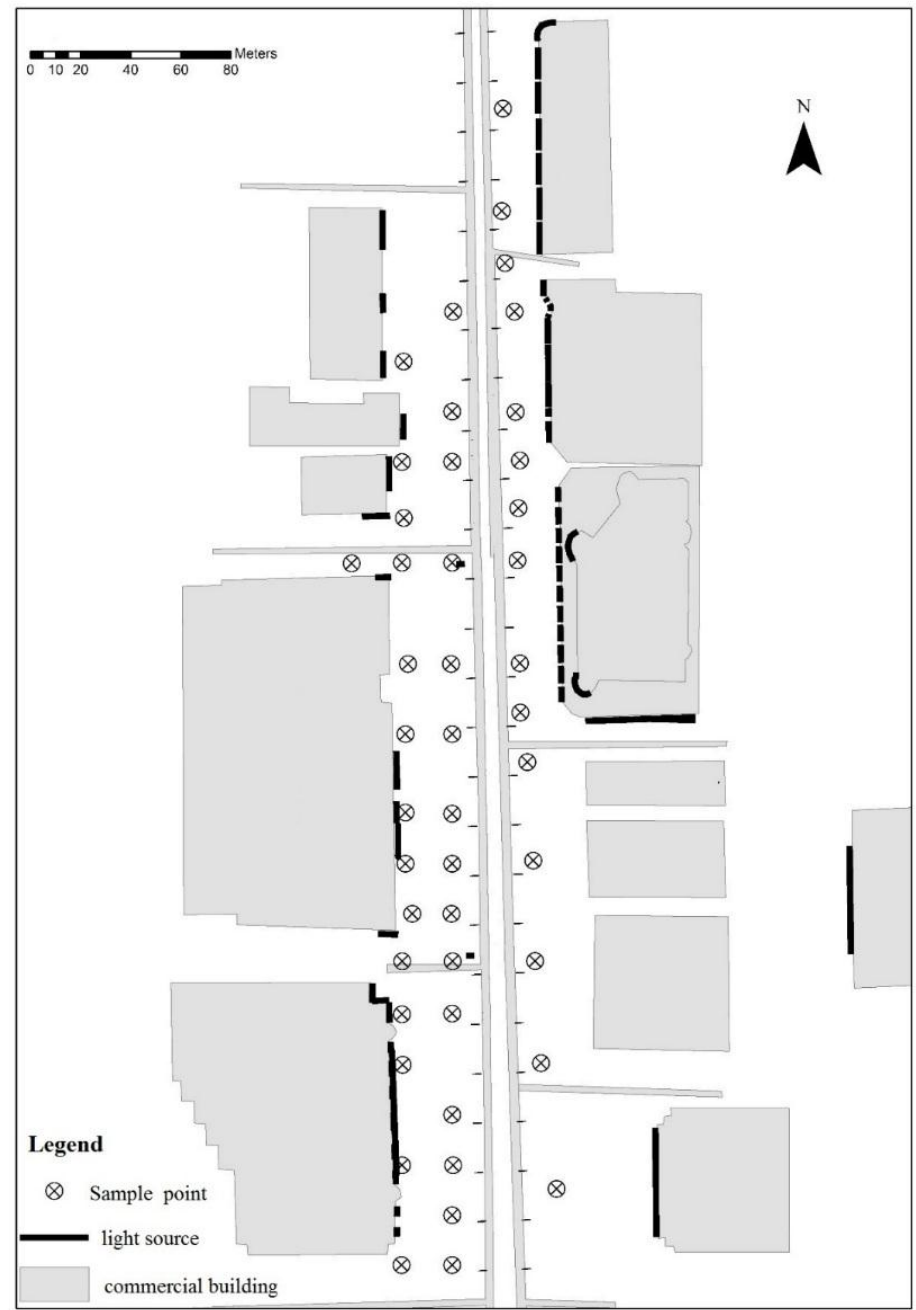

Figure 1. The sample points in the Xidan commercial zone.

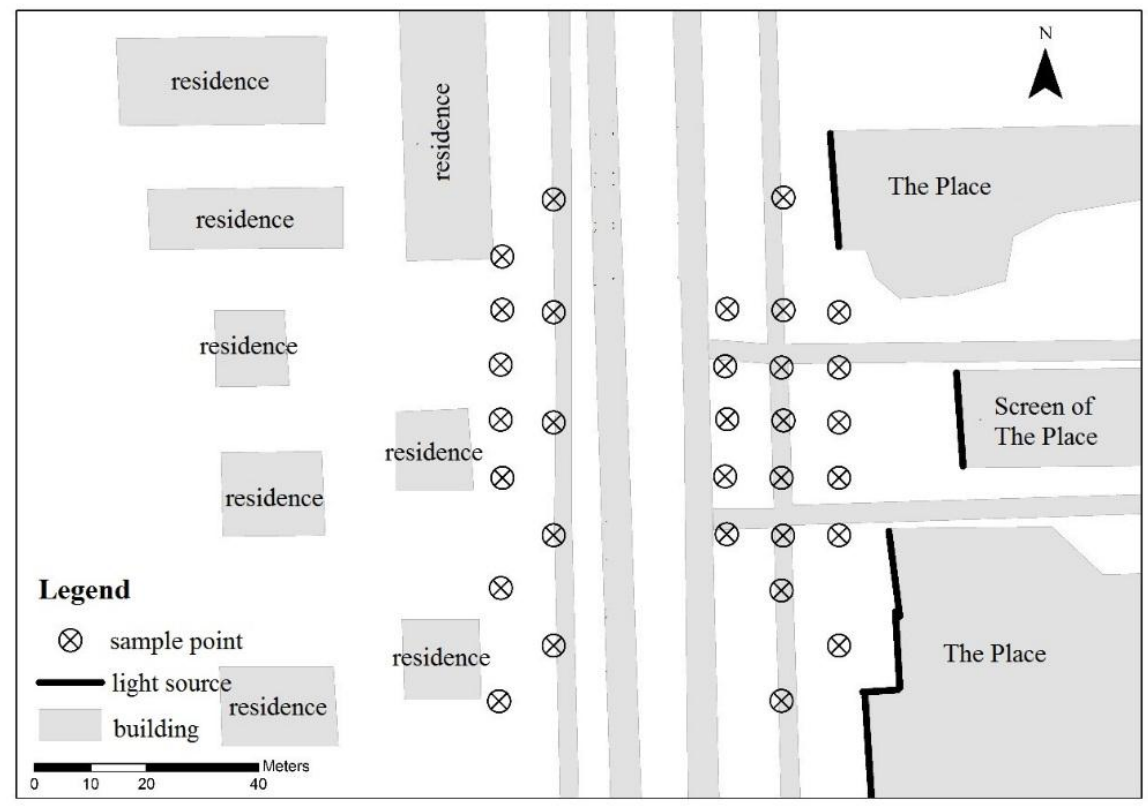

Figure 2. The sample points in The Place mixed-use zone. 
Table 1. Light intensity at every sample point in the Xidan commercial zone.

\begin{tabular}{cccccc}
\hline ID & Light Intensity/Lux & ID & Light Intensity/Lux & ID & Light Intensity/Lux \\
\hline 1 & 25.175 & 16 & 13.075 & 31 & 89.05 \\
2 & 23.575 & 17 & 45.05 & 32 & 18.475 \\
3 & 25.175 & 18 & 61.5 & 33 & 7.625 \\
4 & 34.625 & 19 & 38.175 & 34 & 17.475 \\
5 & 46.15 & 20 & 69.25 & 35 & 10.5 \\
6 & 18.575 & 21 & 42.45 & 36 & 24.225 \\
7 & 32.525 & 22 & 17.5 & 37 & 11.125 \\
8 & 38.45 & 23 & 14.725 & 38 & 44.55 \\
9 & 22.125 & 24 & 29.8 & 39 & 12.475 \\
10 & 15.825 & 25 & 40.65 & 40 & 18.525 \\
11 & 22.075 & 26 & 18.775 & 41 & 25.5 \\
12 & 9.275 & 27 & 31.225 & 42 & 46.35 \\
13 & 21.1 & 28 & 46.025 & 43 & 78.075 \\
14 & 44.9 & 29 & 62.7 & 44 & 109.575 \\
15 & 12.6 & 30 & 106.425 & 45 & 17.75 \\
\hline
\end{tabular}

\subsection{Model of Light Intensity Distribution}

We use the spatial interpolation of GIS technology to model the spatial distribution of light intensity, which can transform the measurement data of discrete points into a continuous data surface. There are different ways to implement spatial interpolation, such as inverse distance weighted interpolation (IDW), the cubic spline interpolation method, the kriging interpolation method, the Pointlnterp method, the natural adjacent method and the trend surface method [34]. The range of application of each method is different. Considering the point light source intensity distance attenuation empirical model [35]:

$$
f_{a t t}(d)=\min \left(\frac{1}{a+b d+c d^{2}}, 1\right)
$$

where $f_{a t t}$ is the attenuation factor and $a, b$ and $c$ are empirical constants, we chose IDW to fit the light intensity distribution. The IDW interpolation method, based on the distance between sample points, determines the weights and calculates the value of the interpolation point; the sample points nearer to the interpolation point will have greater weight. The formula is:

$$
\begin{gathered}
\mathrm{Z}=\left[\sum_{i=1}^{n} \frac{Z i}{d_{i}^{2}}\right] /\left[\sum_{i=1}^{n} \frac{1}{d_{i}^{2}}\right] \\
d_{i}=(X-X i)^{2}+(Y-Y i)^{2}
\end{gathered}
$$

where $X i, Y i, Z i(i=1,2, \ldots, \mathrm{n})$ represent point coordinates and $\mathrm{Z}$ represents the attribute value. The IDW spatial interpolation method is suitable for situations in which there are intensive sampling points continuously distributed in space, and the relationship among attribute values sharply attenuates as distance increases, such as when fitting the space distribution of sound propagation. Because the IDW method cannot reflect any major trends in the data, it cannot be applied to situations such as simulating air pollution distribution under the action of wind. Considering that there is no major impetus of light intensity distribution, we think it is acceptable to use the IDW method to fit the distribution of light intensity.

\subsection{Precision Inspection}

Common approaches to accuracy estimation are the bootstrap method, the cross-validation method and the holdout method [36]. The idea behind the holdout method is to perform the sampling from all of the sampling points and to use the left sample points to interpolate, followed by comparing 
the value of checkpoints and the interpolation value, finally obtaining the precision [36]. We adopt the holdout method and use the analysis of variance (ANOVA) method to evaluate the accuracy of the interpolation results. The ANOVA method can assess the confidence of the current results by comparing the calculative statistical test value and established probability distribution. The $\mathrm{F}$ value is the statistical test; the corresponding probability distribution is the F distribution; and Sig. F is the statistical significance, the probability of the sample result. In many research fields, a Sig. F of less than 0.05 is the widely-accepted error boundary. We reserved some sample points at the proportion of 1:9 as checkpoints before interpolation. The checkpoints are certain to have sufficient quantity and to distribute light at every intensity range (high, medium and low light intensity) to ensure the accuracy of the results.

\section{Results and Analysis}

\subsection{Light Intensity Distribution}

From the interpolation results (Figures 3-5), we can observe that the illuminance of the Xidan commercial zone ranges from 8 lux to 110 lux, and there are major spatial differences. Light intensity on the west side of the road is generally higher than on the east side. Areas of low illumination are usually below the bridge, and areas of high illumination are usually distributed in population-dense areas, such as the mall entrance and the nearby sidewalk. The Wangfujing commercial zone has a wide range of illumination, from a low of 13.71 lux to a high of 314.91 lux. In general, the illumination distribution in the north and south areas is much higher than that of the central area. The average illumination of the north area is approximately 150 lux, and there are individual light point sources that drive up the brightness of the surrounding area. The central part is relatively darker and more homogeneous. The most light-polluted area is the north part of the south area, where illumination is consistently above 300 lux, and unlike the north, its polluted area presents a much wider planar distribution. The illuminance of the Zhongguancun commercial zone ranges from 2 lux to 66 lux; the distribution in the northeast is higher than in the southwest and lower than in the Wangfujing and Xidan commercial areas in general.

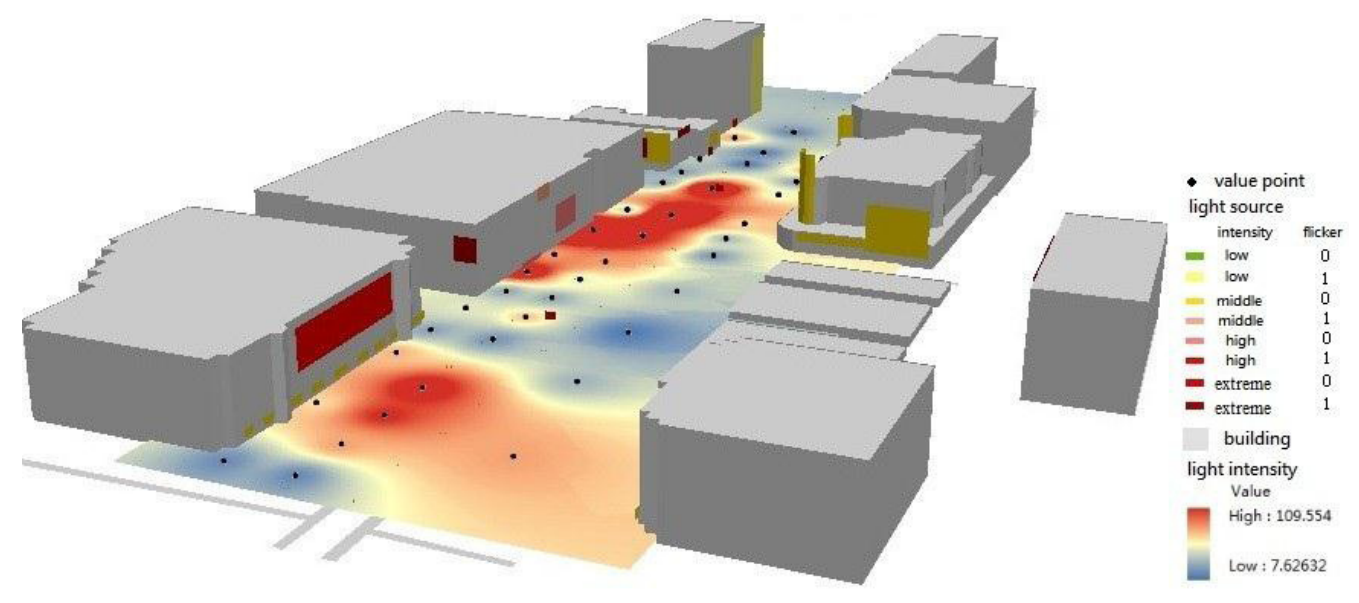

Figure 3. The model of the light intensity distribution in the Beijing Xidan commercial zone (sight direction: southeast). 


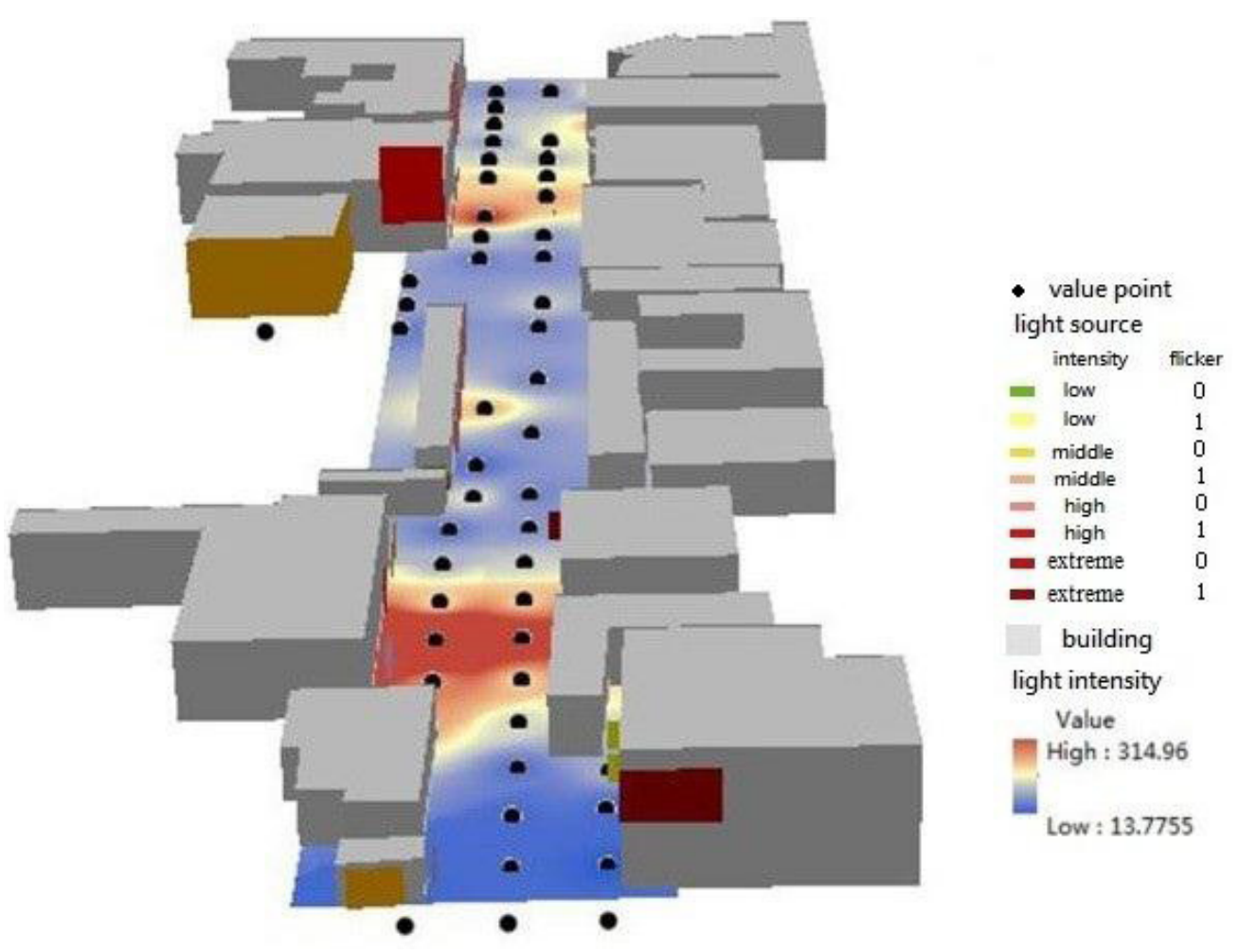

Figure 4. The model of the light intensity distribution in the Beijing Wangfujing commercial zone (sight direction: south).

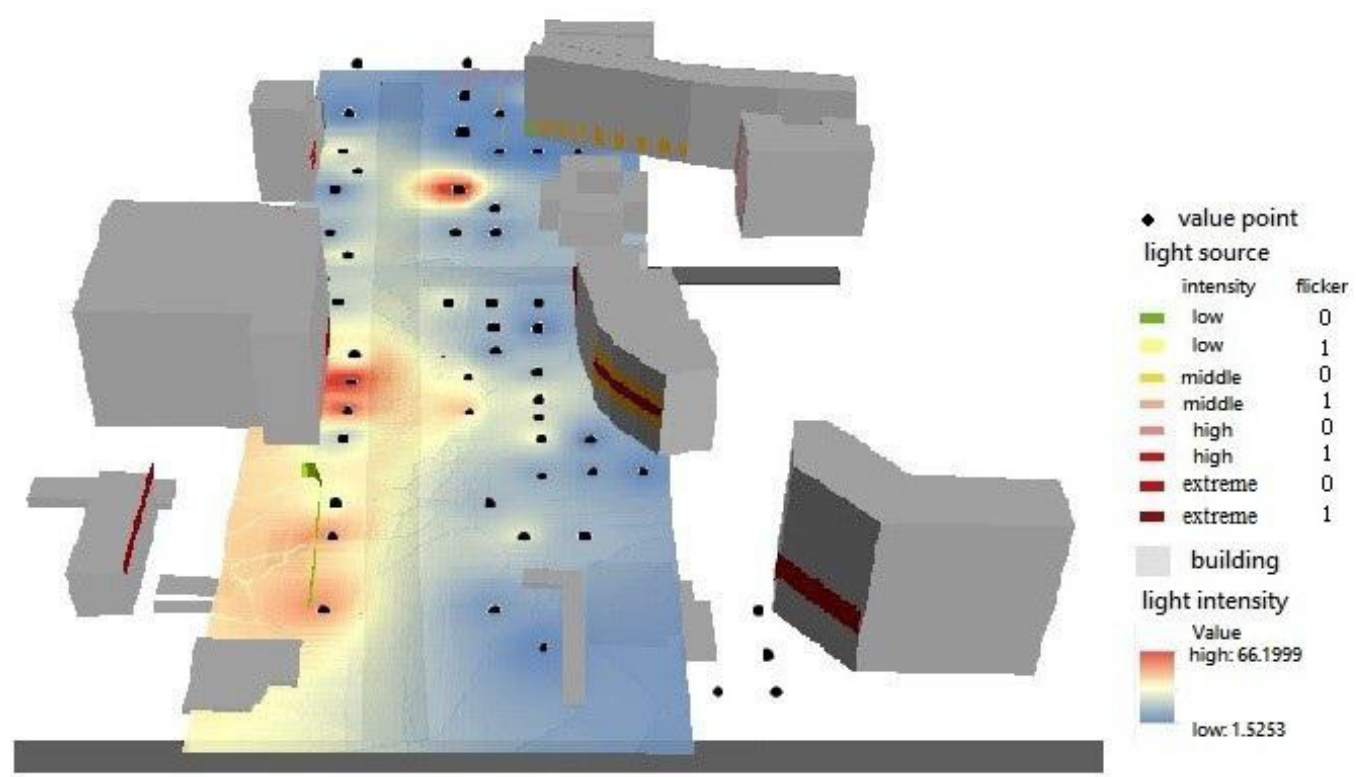

Figure 5. The model of the light intensity distribution in the Beijing Zhongguancun commercial zone (sight direction: southeast).

The International Commission on illumination (CIE) issued its Guide on interior lighting in 1986, in which it was recommended that the illumination intensity of lighting at outdoor locations range from 20 lux to 50 lux. Compared with the norm, all illumination intensities of the three study areas are excessive; this can be seen as light pollution and will cause serious adverse effects on human health. The level of light source intensity is directly influenced by light source intensity, and the size and shape of the light source can strongly influence the spatial scale. The power of these shapes, in order 
from high to low, are planar light sources, linear light sources and point light sources, and the larger, longer light sources will have broader effects. Meanwhile, the height of the light source in relation to the ground and the distance to the sidewalk may also have an influence. Because we monitored the illumination intensity at a height of $1.5 \mathrm{~m}$, under similar conditions, the higher light source will have less influence. In contrast, a light source close to the ground, such as light box advertising at a bus station, which is at the same level as people's horizontal line of sight and usually has a high intensity, can have a greater influence.

\subsection{Precision Inspection of Simulation}

To test the effectiveness of the interpolation results, we set aside one tenth of the measured points, before interpolation, as check values. To obtain more reliable results, the selection of check values must not only be sufficient in total number, but also follow the method of stratified sampling, ensuring that there are check values within every range of light intensity. The results of correlation analysis are shown in Table 2. We can see that the Sig. F values of all prediction models are less than 0.05 , which proves that there is $95 \%$ reliability that using the inverse distance weighted interpolation model to simulate the spatial distribution of light intensity is effective. This finding means that the space distance attenuation of light intensity accords with the inverse distance weighted interpolation rule, and we can use the IDW interpolation method to simulate the spatial distribution of light intensity in the practical application at a high accuracy.

Table 2. Interpolation precision test results. Sig., significance.

\begin{tabular}{ccccc}
\hline Model & R & R-Square & Adjusted R-Square & Sig. F \\
\hline Xidan & 0.978 & 0.957 & 0.943 & 0.004 \\
Wangfujing & 0.883 & 0.779 & 0.706 & 0.047 \\
Zhongguancun & 0.977 & 0.955 & 0.943 & 0.001 \\
\hline
\end{tabular}

\subsection{Light Pollution in Residences}

Using the IDW interpolation method, we take the northwest corner (zero height) of our study area as the origin of the coordinates and establish the space rectangular coordinate system; the interpolation results are shown in Figure 6. We find that the illumination intensity is the highest in the screen position and shows concentric spherical diffusion, decreasing just the same as the intensity of the point light source attenuates with distance.

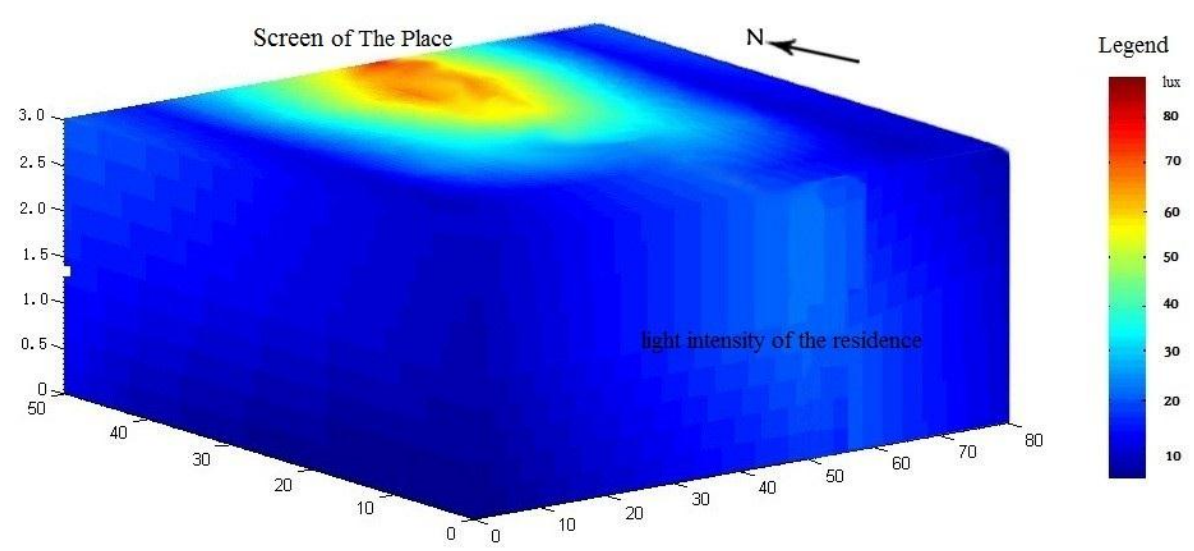

Figure 6. The model of the light intensity distribution in the mixed-use zone (sight direction: northwest).

With the illumination of The Place's screen, the vertical illuminance at the residential building across the street ranges from 0 lux to 30 lux. The building directly facing the screen is affected 
more severely than the others. Comparing the light intensity at $1.5 \mathrm{~m}$ above the ground and at $3 \mathrm{~m}$, we observe that the light intensity at $3 \mathrm{~m}$ is higher than at $1.5 \mathrm{~m}$ (Figures 7 and 8 ); and despite the limited expenditure and research on this issue and the lack of more layered data, we can nevertheless deduce that the light intensity will continue to increase as height increases within a certain range. Thus, residences on higher floors will suffer from more intense light pollution. From the cross-section, we can see that the border trees (at a projection distance of approximately $50 \mathrm{~m}$ to the screen) have played some role in blocking out light, but do little to block the windows' vertical illuminance. According to the measured data, the vertical illumination at the residential buildings' windows ranges from 2 lux to 23 lux; the illumination in some areas is far higher than the CIE's recommended value of 11 lux of window vertical illuminance after curfew. Consider first floor residents' window vertical illuminance as an example (Figure 9). We observe that nearly $48.6 \%$ of the area suffers from light pollution, which seriously interferes with residents' daily lives and has a serious influence on their rest and health. Although The Place has a fixed show time, 17:30 to 23:00 in summer and 17:00 to 22:00 in winter, the residents who participated in our interview still reported strong dissatisfaction with light pollution. Clearly, light pollution in mixed-use areas that include both commercial and residential buildings demands prompt solutions; current designs of light intensity and lighting time are unreasonable and lack compensation mechanisms for residents impacted by light pollution.
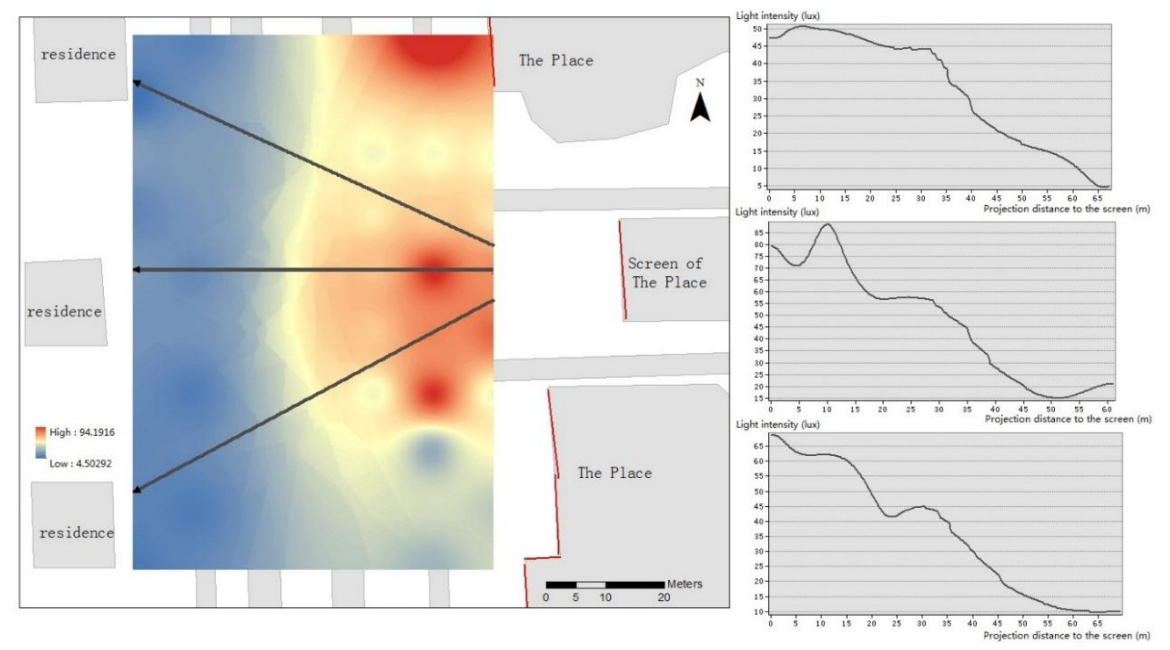

Figure 7. Light intensity distribution at a 1.5-m height.

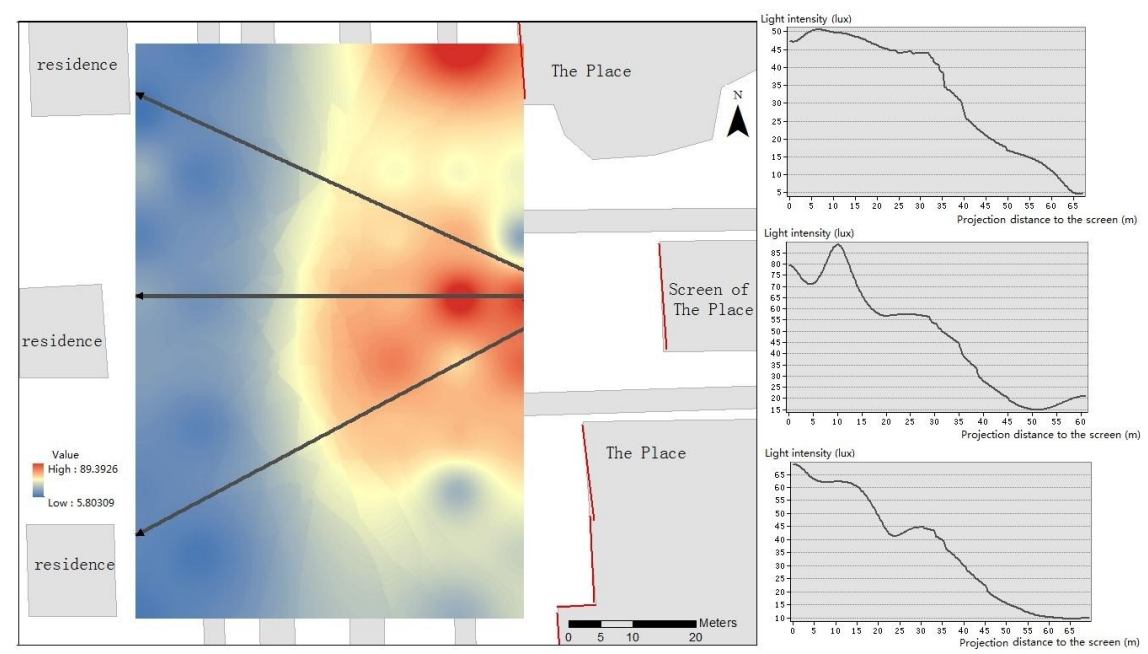

Figure 8. Light intensity distribution at a 3-m height. 


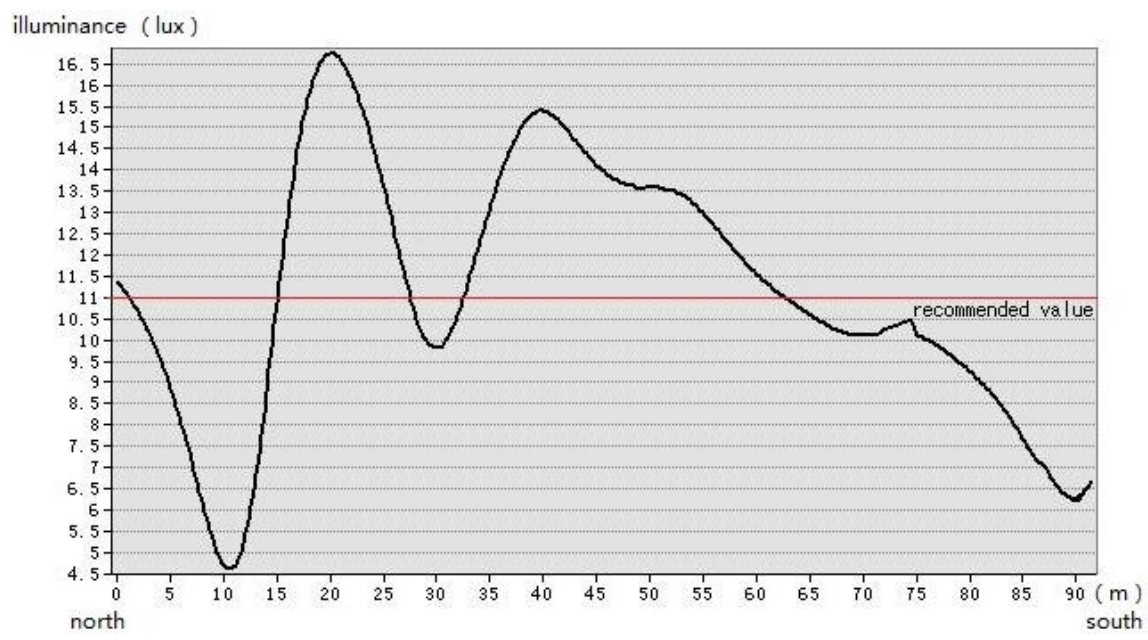

Figure 9. Light illumination of the first floor residence in the Dongdaqiao Community.

\section{Results and Recommendations}

Above all, we can conclude that the spatial distribution of light intensity is in accordance with the spatial interpolation pattern and can be fitted using the IDW method with high precision (above 95\%). Furthermore, this approach can be used in three dimensions to quantitatively evaluate the distribution of light intensity. Due to the limitations of funding and existing research, we only tested three layers $(0 \mathrm{~m}, 1.5 \mathrm{~m}, 3 \mathrm{~m})$. In a practical application of our approach, the manipulator could add sampling heights and layers and adjust the sample number and the dot spacing according to the size of the study area and the accuracy requirements of the evaluation.

From our empirical research, we can observe that different degrees of excessive lighting are generally present in the Beijing commercial zone. The highest illumination intensity of the commercial zone is several times higher than the value recommended by the CIE, which is a major waste of funds and energy and causes serious damage to pedestrians. It is the light pollution in the mixed-use zone that has the greatest influence on residents' biological clocks. Lighting design is currently excessively focused on economic benefits and is ignoring the basic requirements of human wellbeing.

Objectively, Beijing's lighting project has brought some economic benefits, and it has created a series of new landscapes. However, according to our research, there are problems in the selection of light sources, their layout, and so on. The excessive pursuit of economic benefits, blind comparisons of brightness, lack of scientific guidance and lack of attention to human wellbeing have all led to light pollution in Beijing, causing a great waste of energy, causing damage to civilians and proving the vulnerability of the legislative system. Based on our research results, we offer some suggestions. First, based on the relevant recommended illumination value by CIE in different function areas, Beijing should scientifically plan its lighting system and replace high-intensity light sources, especially in commercial zones (20 lux to 50 lux) and mixed-use zones (not higher than 11 lux after curfew). Meanwhile, it is important to balance the light intensity of the entire area on the basis of the beauty and diversity of the lighting system to provide residents with a soft outdoor lighting environment. Second, combined with light intensity, the light spectra, duration and timing of light should also be paid great attention. For example, after 8:00 p.m., the videos played on the LED screen should not choose a blue hue, which may cause the most adverse influence on residents' sleeping [34,37]. Third, the planning of lighting should be coordinated with other types of planning. For example, the layout of light sources should be compatible with regional road planning and should provide effective visual guidance. The illuminance value of light sources in commercial zones should be reduced to avoid affecting traffic signal discrimination. Finally, Beijing should optimize its laws and regulations to prohibit brightness 
comparisons, protect the rights of residents and establish distinguished compensation mechanisms for light pollution, based on the light-contaminated area and the exceeding degree.

Acknowledgments: This work has received funds from Science \& Technology Basic Resources Investigation Program of China (Reference No. 2017FY101303) and the sub-project The Special Database Construction of Rusia, Mongolia and China of "The Belt and Road" Data Integrated Platform Construction Project of Institute of Geographic Sciences and Natural Resources Research, Chinese Academy of Science.

Author Contributions: Xueting Jin and Huiping Liu conceived and designed the experiments; Xueting Jin and Jinzhou Zhang performed the experiments; Xueting Jin and Yu Li analyzed the data; Xueting Jin, Jinzhou Zhang and Ji Zheng wrote the paper.

Conflicts of Interest: The authors declare no conflict of interest.

\section{References}

1. Lilensten, J.; Moen, J.; Barthélemy, M.; Thissen, R.; Simon, C.; Lorentzen, D.A.; Dutuit, O.; Amblard, P.O.; Sigernes, F. Polarization in aurorae: A new dimension for space environments studies. Geophys. Res. Lett. 2008, 35. [CrossRef]

2. Cinzano, P.; Falchi, F.; Elvidge, C.D. The first world atlas of the artificial night sky brightness. Mon. Not. R. Astron. Soc. 2001, 328, 689-707. [CrossRef]

3. Crawford, D.L. Light pollution, an environmental problem for astronomy and for mankind. J. Ital. Astron. Soc. 2000, 71, 11-15.

4. Riegel, K.W. Lightpollution. Science 1973, 179, 1285-1291. [CrossRef] [PubMed]

5. Lockley, S.W. Timed melatonin treatment for delayed sleep phase syndrome: The importance of knowing circadian phase. Sleep 2005, 28, 1214-1216. [PubMed]

6. Caddick, Z.A.; Gregory, K.; Flynn-Evans, E.E. Sleep environment recommendations for future spaceflight vehicles. In Advances in Human Aspects of Transportation; Springer: Cham, Switzerland, 2017; pp. 923-933.

7. Falchi, F.; Cinzano, P.; Elvidge, C.D.; Keith, D.M.; Haim, A. Limiting the impact of light pollution on human health, environment and stellar visibility. J. Environ. Manag. 2011, 92, 2714-2722. [CrossRef] [PubMed]

8. Muro, M. Light pollution-development blocked near Tucson telescopes. Science 1999, 283, 469. [CrossRef]

9. Gallaway, T. On light pollution, passive pleasures, and the instrumental value of beauty. J. Econ. Issues 2010, 44, 71-88. [CrossRef]

10. California Energy Commission. Non-Residential Compliance Manual for California's 2005 Energy Efficiency Standards; California Energy Commission: Sacramento, CA, USA, 2005.

11. Verheijen, F.J. Photopollution artificial light optic spatial control-systems fail to cope with incidents, causations, remedies. Exp. Biol. 1985, 44, 1-18. [PubMed]

12. Rodriguez, A.; Rodriguez, B.; Curbelo, A.J.; Perez, A.; Marrero, S.; Negro, J.J. Factors affecting mortality of shearwaters stranded by light pollution. Anim. Conserv. 2012, 15, 519-526. [CrossRef]

13. McKinney, M.L.; Schoch, R.M.; Yonavjak, L. Environmental Science: Systems and Solutions; Jones \& Bartlett Publishers: Sudbury, MA, USA, 2007.

14. Davis, S.; Mirick, D.K.; Stevens, R.G. Night shift work, light at night, and risk of breast cancer. J. Natl. Cancer Inst. 2001, 93, 1557-1562. [CrossRef] [PubMed]

15. Stevens, R.G. Artificial lighting in the industrialized world: Circadian disruption and breast cancer. Cancer Causes Control 2006, 17, 501-507. [CrossRef] [PubMed]

16. Wright, K.P.; Hughes, R.J.; Kronauer, R.E.; Dijk, D.J.; Czeisler, C.A. Intrinsic near-24-h pacemaker period determines limits of circadian entrainment to a weak synchronizer in humans. Proc. Natl. Acad. Sci. USA. 2001, 98, 14027-14032. [CrossRef] [PubMed]

17. Kerenyi, N.A.; Pandula, E.; Feuer, G. Why the incidence of cancer is increasing the role of light pollution. Med. Hypotheses 1990, 33, 75-78. [CrossRef]

18. Pun, C.S.; So, C.W. Night-sky brightness monitoring in Hong Kong: A city-wide light pollution assessment. Environ. Monit. Assess. 2012, 184, 2537-2557. [CrossRef] [PubMed]

19. Marchant, P.R. A demonstration that the claim that brighter lighting reduces crime is unfounded. Br. J. Criminol. 2004, 44, 441-447. [CrossRef]

20. Olsen, R.N.; Gallaway, T.; Mitchell, D. Modelling us light pollution. J. Environ. Plan. Manag. 2013, 57, 883-903. [CrossRef] 
21. Lewy, A.J.; Wehr, T.A.; Goodwin, F.K.; Newsome, D.A.; Markey, S.P. Light suppresses melatonin secretion in humans. Science 1980, 210, 1267-1269. [CrossRef] [PubMed]

22. Lyytimäki, J.; Tapio, P.; Assmuth, T. Unawareness in environmental protection: The case of light pollution from traffic. Land Use Policy 2012, 29, 598-604. [CrossRef]

23. Chalkias, C.; Petrakis, M.; Psiloglou, B.; Lianou, M. Modelling of light pollution in suburban areas using remotely sensed imagery and GIS. J. Environ. Manag. 2006, 79, 57-63. [CrossRef] [PubMed]

24. Lu, F.; Xu, J. Chinese regional economic inequalities based on the two-stage nested theil decomposition method. Sci. Geogr. Sin. 2005, 15, 401-407.

25. Narisada, K.; Schreuder, D. Light Pollution Handbook, 1st ed.; Springer: Dordrecht, The Netherlands, 2004.

26. Light Pollution Science and Technology Institute. IDA European Meeting Report; Cinzano, P., Ed.; Light Pollution Science and Technology Institute: Thiene, Italy, 2002.

27. Han, P.; Huang, J.; Li, R.; Wang, L.; Hu, Y.; Wang, J.; Huang, W. Monitoring trends in light pollution in China based on nighttime satellite imagery. Remote Sens. 2014, 6, 5541-5558. [CrossRef]

28. Gallaway, T.; Olsen, R.N.; Mitchell, D.M. The economics of global light pollution. Ecol. Econ. 2010, 69, 658-665. [CrossRef]

29. Liu, J. Nearly Half of Respondents Were Suffering Severely Light Pollution. Available online: http://news. ifeng.com/a/20141121/42535857_0.shtml (accessed on 21 November 2014). (In Chinese)

30. Xiao, X.P. Dazzling LED Advertising Screen. Available online: http://sztqb.sznews.com/html/2012-08/22/ content_2171558.htm (accessed on 22 August 2012). (In Chinese)

31. Chepesiuk, R. Missing the dark health effects of light pollution. Environ. Health Perspect. 2009, 117, A20-A27. [CrossRef] [PubMed]

32. Shi, K.; Yu, B.; Huang, Y.; Hu, Y.; Yin, B.; Chen, Z.; Chen, L.; Wu, J. Evaluating the ability of npp-viirs nighttime light data to estimate the gross domestic product and the electric power consumption of china at multiple scales: A comparison with dmsp-ols data. Remote Sens. 2014, 6, 1705-1724. [CrossRef]

33. Rebecca, M. Nighttime Light Pollution Covers Nearly $80 \%$ of the Globe. Available online: http:/ /www.bbc. com/news/science-environment-36492596 (accessed on 10 June 2016).

34. Tobler, W.R. A computer movie simulation urban growth in the Detroit. Econ. Geogr. 1970, 46, $234-240$. [CrossRef]

35. Foley, J.D. Computer Graphic Principal and Practice, 2nd ed.; China Machine Press: Beijing, China, 2002; pp. 722-731. (In Chinese)

36. Kohavi, R. A study of cross-validation and bootstrap for accuracy estimation and model selection. In Proceedings of the International Joint Conference on Artificial Intelligence, Montreal, QC, Canada, 20-25 August 1995.

37. Lockley, S.W.; Evans, E.E.; Scheer, F.A.J.L.; Brainard, G.C.; Czeisler, C.A.; Aeschbach, D. Short-wavelength sensitivity for the direct effects of light on alertness, vigilance, and the waking electroencephalogram in humans. Sleep 2006, 29, 161-168. [PubMed]

(C) 2017 by the authors. Licensee MDPI, Basel, Switzerland. This article is an open access article distributed under the terms and conditions of the Creative Commons Attribution (CC BY) license (http://creativecommons.org/licenses/by/4.0/). 